9. S.J. Liao, K.L. Wong, and L.C. Chou, Small-size uniplanar coupledfed PIFA for 2.4/5.2/5.8 GHz WLAN operation in the laptop computer, Microwave Opt Technol Lett 51 (2009), 1023-1028.

10. K.L. Wong and W.J. Chen, Small-size microstrip-coupled printed PIFA for $2.4 / 5.2 / 5.8 \mathrm{GHz}$ WLAN operation in the laptop computer, Microwave Opt Technol Lett 51 (2009).

11. K.L. Wong, Planar antennas for wireless communications, Wiley, New York, 2003.

12. C.H. Chang and K.L. Wong, Internal coupled-fed shorted monopole antenna for GSM850/900/1800/1900/UMTS operation in the laptop computer, IEEE Trans Antennas Propag 56 (2008), 3600-3604.

13. K.L. Wong and L.C. Lee, Multiband printed monopole slot antenna for WWAN operation in the laptop computer, IEEE Trans Antennas Propag 57 (2009), 324-330.

14. K.L. Wong and S.J. Liao, Uniplanar coupled-fed printed PIFA for WWAN operation in the laptop computer, Microwave Opt Technol Lett 51 (2009), 549-554.

15. K.L. Wong and F.H. Chu, Internal planar WWAN laptop computer antenna using monopole slot elements, Microwave Opt Technol Lett 51 (2009), 1274-1279.

16. K.L. Wong, C.H. Chang, B. Chen, and S. Yang, Three-antenna MIMO system for WLAN operation in a PDA phone, Microwave Opt Technol Lett 48 (2006), 1238-1242.

17. G. Chi, B. Li, and D. Qi, Dual-band printed diversity antenna for 2.4/5.2-GHz WLAN application, Microwave Opt Technol Lett 45 (2005), 561-563.

18. K.J. Kim and W.H. Ahn, The high isolation dual-band inverted F antenna diversity system with the small $\mathrm{N}$-section resonators on the ground plane, Microwave Opt Technol Lett 49 (2007), 731-734.

19. M. Karaboikis, C. Soras, G. Tsachtsiris, and V. Makios, Compact dual-printed inverted-F antenna diversity systems for portable wireless devices, IEEE Antennas Wireless Propag 3 (2004), 9-14.

20. Y. Gao, C.C. Chiau, X. Chen, and C.G. Parini, Modified PIFA and its array for MIMO terminals, IEE Proc Microwave Antennas Propag 152 (2005), 255-259.

21. K.L. Wong, Y.Y. Chen, S.W. Su, and Y.L. Kuo, Diversity dualband planar inverted-F antenna for WLAN operation, Microwave Opt Technol Lett 38 (2003), 223-225.

22. C.T. Lee, K.L. Wong, and Y.C. Lin, Wideband monopole antenna for DTV/GSM operation in the mobile phone, Microwave Opt Technol Lett 50 (2008), 801-806.

23. T.W. Kang and K.L. Wong, Chip-inductor-embedded small-size printed strip monopole for WWAN operation in the mobile phone, Microwave Opt Technol Lett 51 (2009), 966-971.

24. Ansoft Corporation HFSS, available at:http://www.ansoft.com/ products/hf/hfss/.

(C) 2009 Wiley Periodicals, Inc.

\section{NANOELECTROMECHANICAL SWITCHES FOR RECONFIGURABLE ANTENNAS}

\author{
Bedri A. Cetiner, ${ }^{1}$ Necmi Biyikli, ${ }^{2}$ Bahadir S. Yildirim, ${ }^{3}$ \\ and Yasin Damgaci ${ }^{1}$ \\ ${ }^{1}$ Department of Electrical and Computer Engineering, Utah State \\ University, Logan, UT 84341; Corresponding author: \\ bedri@engineering.usu.edu \\ ${ }^{2}$ UNAM-Institute of Materials Science and Nanotechnology, \\ Bilkent University, Bilkent, Ankara 06800, Turkey \\ ${ }^{3}$ MEMSComm LLC, KY 40351
}

Received 24 April 2009

ABSTRACT: We report on the full-wave analyses of a frequency reconfigurable antenna integrated with metallic nanoelectromechanical system (NEMS) switches (length $=3 \mu \mathrm{m}$, width $=60 \mathrm{~nm}$ ). The NEMS switch used in this work has the same architecture with low voltage, double-arm cantilever-type metallic DC-contact microelectromechanical system (MEMS) switch recently developed in author's group. The microfabrication and characterization of the MEMS switch have also been given in this article. (C) 2009 Wiley Periodicals, Inc. Microwave Opt Technol Lett 52: 64-69, 2010; Published online in Wiley InterScience (www.interscience.wiley.com). DOI 10.1002/mop.24833

Key words: multifunctional reconfigurable antenna; microelectromechanical system (MEMS) switch; nanoelectromechanical system (NEMS) switch; full-wave electromagnetic analysis

\section{INTRODUCTION}

The multifunctional reconfigurable antenna (MRA) concept [1] has gained significant interest due to the following two main factors: (A) A single MRA that can perform multiple functions by dynamically changing its properties (operating frequency, polarization, radiation pattern, etc) can replace multiple singlefunction legacy antennas, thereby providing a significant reduction in the overall size of multimode multiband wireless communication systems. (B) Reconfigurable antenna properties of an MRA can be used as important additional degrees of freedom in adaptive system parameters as first proposed in Ref. [2], which was further studied [3].

To dynamically change the properties of an MRA, the current distribution over the volume of the antenna needs to be changed, where each distribution corresponds to a different mode of operation. To this end, one can change the geometry of the antenna by switching on and off various geometrical metallic segments that make up the MRA. For switching, microelectromechanical system (MEMS), nanoelectromechanical system (NEMS) or semiconductor type switches can be employed. MEMS and NEMS type switches are advantageous over semiconductor type switches mainly due to the monolithic integration capability with antenna segments, which eliminates interconnect losses, along with their very low loss and power characteristics [4]. However, standard MEMS switches require high actuation voltages $(30-80 \mathrm{~V})$ and posses low switching speeds (10-20 $\mu \mathrm{s})$, which may not be appropriate for next generation cognitive wireless communications applications. In these systems, the reconfigurability must be fast enough ( less than 1 $\mu \mathrm{s})$ to respond to short term channel statistics and to support most dynamic adaptation schemes such as opportunistic beamforming schemes. We have recently developed a double-arm DC-contact small-size MEMS switch [5] of which schematic and SEM picture are shown in Figure 1. Due to its small-size, cantilever length $(L=5-50 \mu \mathrm{m})$ and width $(W=2-40 \mu \mathrm{m})$, i.e., 10-100 times smaller in lateral dimensions than a standard MEMS switch, this switch showed actuation voltages lower than $10 \mathrm{~V}$. We have chosen DC-contact switches over their capacitive contact counterparts due to their wide frequency range of operation, which is compatible with IEEE 802.11 WLAN standards.

The article is organized as follows: first, we briefly present the microfabrication and RF characterization of the reduced-size MEMS switches. Next, the full-wave analyses of a frequency reconfigurable antenna integrated with NEMS switches are given. This antenna, namely NEMS integrated penta-band PIFA can operate over five frequency bands of GSM900, GPS1575, GSM1800, PCS1900, and UMTS2100.

\section{REDUCED-SIZE MEMS SWITCH: MICROFABRICATION AND RF CHARACTERIZATION}

\subsection{Microfabrication}

The double-arm MEMS actuators were fabricated on a synthetic quartz substrate using a six-layer microwave compatible 

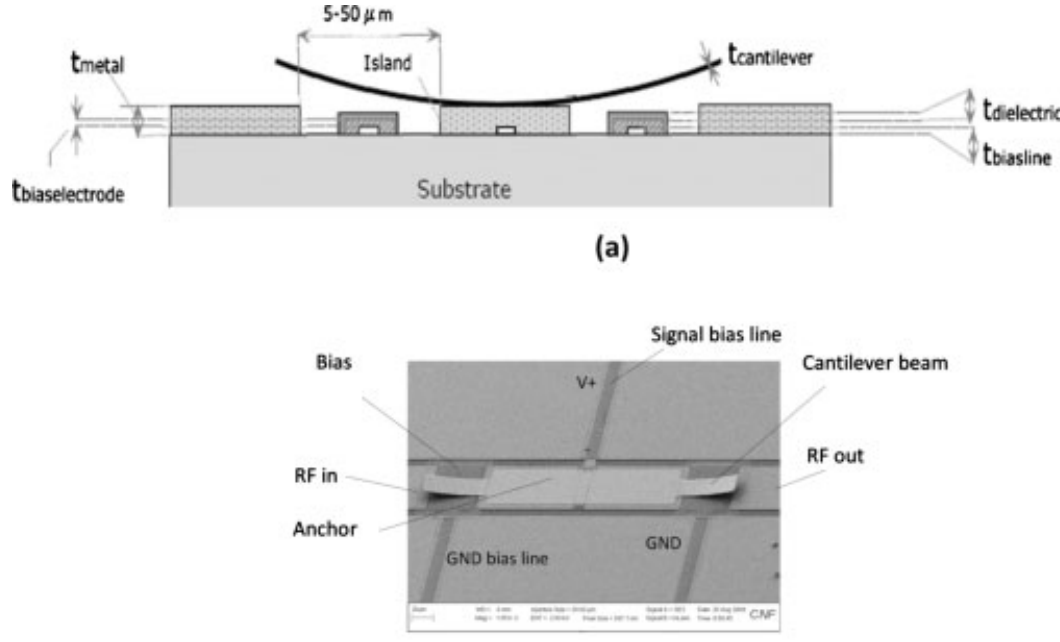

(a)

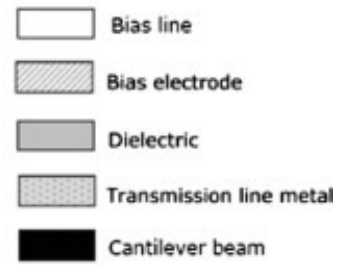

(b)

Figure 1 (a) Schematic and (b) Scanning electron microscopy picture of a DC-contact double-arm cantilever type NEMS switch with typical dimensions: Cantilever width $=1-40 \mu \mathrm{m}, t_{\text {metal }}=0.4-1 \mu \mathrm{m}, t_{\text {cantilever }}=0.2-2 \mu \mathrm{m}, t_{\text {biaselectrode }} \sim 0.2 \mu \mathrm{m}, t_{\text {biasline }}=0.1-0.2 \mu \mathrm{m}$, and $t_{\text {dielectric }} \sim 0.2 \mu \mathrm{m}$

fabrication process. Relative dielectric constant and loss tangent of the quartz substrate for the frequency range of $0.1-30 \mathrm{GHz}$ are 3.9 and $\sim 0.0002$, respectively. Figure 2 shows the step-bystep fabrication procedure. First, the bias lines were formed by a $\sim 150 \mathrm{~nm}$-thick Ti/Cr layer deposited by DC-sputtering. Bias electrode pads were formed with an e-beam evaporated $\sim 200$ $\mathrm{nm}$-thick $\mathrm{Ti} / \mathrm{Cu}$ layer. Afterward, bias lines and bias electrodes were passivated with a 250 nm-thick $\mathrm{SiO}_{2}$ dielectric layer deposited at $275^{\circ} \mathrm{C}$ with a plasma-enhanced chemical vapor-deposition (PECVD) system. In the fourth step, using the e-beam evaporation system, a $1.0 \mu \mathrm{m}$-thick $\mathrm{Ti} / \mathrm{Cu}$ metal layer was deposited as a microwave coplanar waveguide (CPW) on which the switch was realized. A thick $(\sim 2 \mu \mathrm{m})$ amorphous $\mathrm{Si}(\mathrm{a}: \mathrm{Si})$ sacrificial layer was deposited in the PECVD system at $200^{\circ} \mathrm{C}$. Our process optimization efforts showed that the chemical-me- chanical polishing (CMP) planarization of the sacrificial layer was of critical importance for the successful release and mechanical integrity of subsequently deposited cantilevers. In the final step, a $\sim 0.4 \mu$ m-thick TiW layer was DC-sputtered to form the cantilevers, which were subsequently patterned using $\mathrm{CF}_{4}$ based reactive ion etch (RIE). The release of the cantilevers was completed in a $\mathrm{XeF}_{2}$ — etcher system where the underlying a:Si sacrificial layer was effectively etched at lateral etch rates more than $10 \mu \mathrm{m} / \mathrm{min}$. The cantilevers curled upward as expected after the release process, due to the internal stress-gradient within the deposited TiW.

\subsection{RF Measurements}

MEMS actuators of various lateral cantilever sizes with length $(L=5-50 \mu \mathrm{m})$ and width $(W=2-40 \mu \mathrm{m})$ were fabricated and
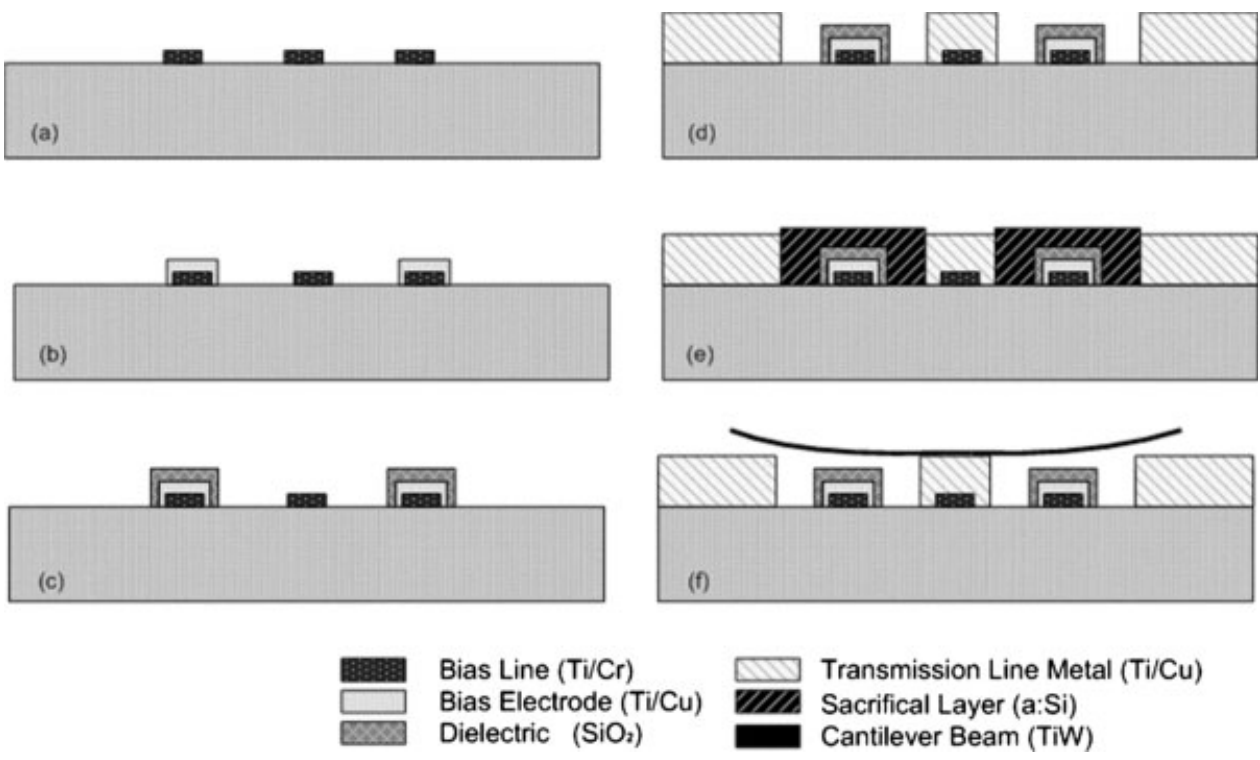

Bias Line $(\mathrm{Ti} / \mathrm{Cr})$ Bias Electrode $(\mathrm{Ti} / \mathrm{Cu})$ Dielectric $\left(\mathrm{SiO}_{2}\right)$

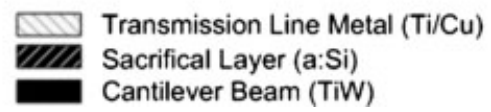

Figure 2 Fabrication process steps for the double-arm DC-contact MEMS actuators: (a) Deposition of Ti/Cr DC bias lines, (b) Ti/Cu bias electrode metal deposition, (c) $\mathrm{SiO}_{2}$ dielectric layer deposition, (d) Ti/Cu transmission line (CPW) metal formation, (e) a:Si sacrificial layer deposition and planarization, and (f) TiW cantilever formation and release process 


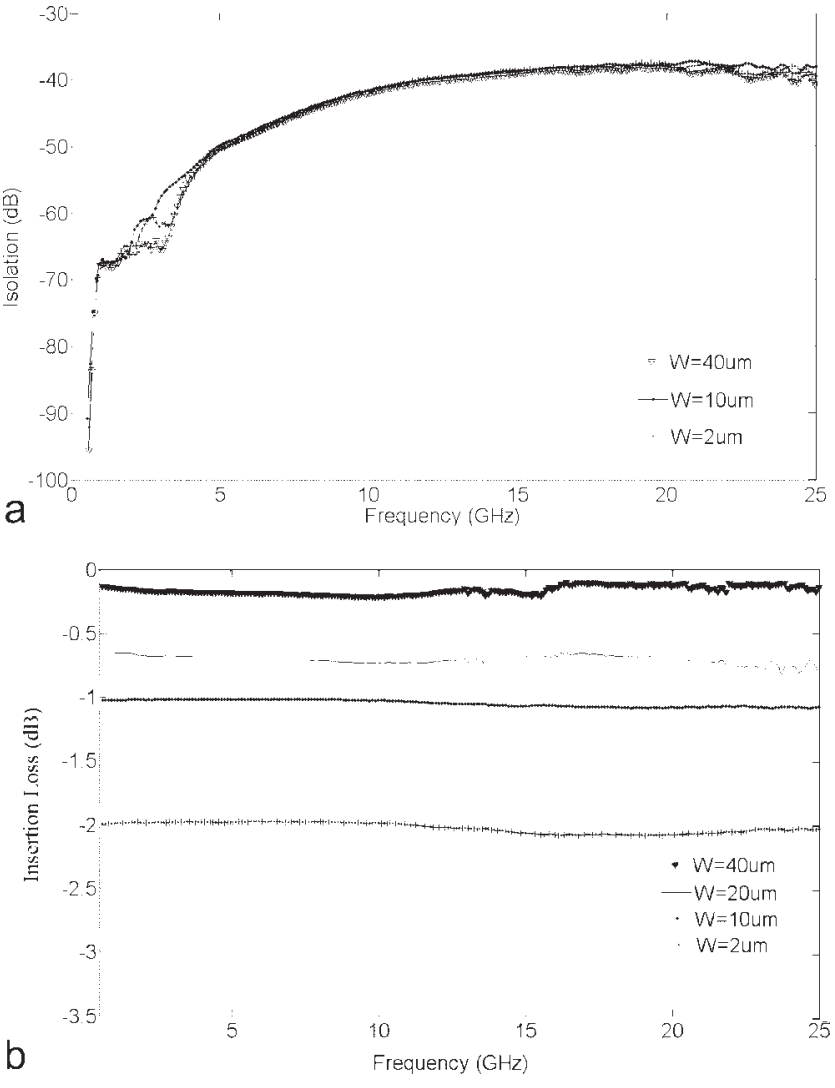

Figure 3 Measured (a) isolation and (b) insertion loss of the fabricated DC-contact MEMS double-arm actuator for membrane widths, $W=$ $40 \mu \mathrm{m}, 20 \mu \mathrm{m}, 10 \mu \mathrm{m}$, and $2 \mu \mathrm{m}$

characterized. The actuation (pull-down) voltage of devices was measured on-wafer using a probe station and a DC bias source. For cantilever widths smaller than $20 \mu \mathrm{m}$, actuation voltages lower than $10 \mathrm{~V}$ were consistently measured. The RF performances of fabricated MEMS actuators have been characterized by measuring small-signal S-parameters by using a probe station with $40 \mathrm{GHz}$ RF probes and a $26 \mathrm{GHz}$ network analyzer. The actuators exhibited excellent isolation (average of $50 \mathrm{~dB}$ ) of the zero-bias open-state (OFF-state) for any of the cantilever dimensions as shown in Figure 3(a). Figure 3(b) shows the measured insertion losses of the biased actuator (ON-state) for different cantilever dimensions as a function of frequency. As is seen from Figure 3, insertion loss steadily increases for decreasing membrane dimensions, which is an indication that the contact resistance gets larger as the membrane width gets smaller. The insertion loss is relatively constant over the frequency range of $100 \mathrm{MHz}-25 \mathrm{GHz}$, which is consistent with the constant loss prediction of real resistance, $S_{21}=2 Z_{0} /\left(2 Z_{0}+R_{c}\right)$, where $R_{\mathrm{c}}$ is the contact resistance. The average insertion loss is at around $0.2 \mathrm{~dB}$ for $40 \mu \mathrm{m}$ wide actuators, whereas it degrades to around $2 \mathrm{~dB}$ for $2 \mu \mathrm{m}$ wide actuators.

\section{FULL-WAVE ANALYSES OF NEMS INTEGRATED PENTA-BAND PIFA}

\subsection{Antenna Geometry and Working Mechanism}

Figure 4 shows the geometry and associated dimensions of the MRA planar inverted-F antenna (PIFA), which operates over five frequency bands of GSM900, GPS1575, GSM1800, PCS1900, and UMTS2100 to achieve the capability of global roaming with a single handset. The antenna is built upon on a synthetic quartz substrate with dimensions of $40 \times 22 \times 7$ $\left(\mathrm{mm}^{3}\right)$ and this structure is then located on a printed circuit board (PCB), which has the dimensions of $100 \times 50 \times 1$ $\left(\mathrm{mm}^{3}\right)$. The PCB surface is covered by a $\mathrm{Cu}$ layer and it is intended to act as a handset RF ground plane. The total height of the antenna from the ground plane is $7 \mathrm{~mm}$, which is the thickness of the quartz substrate.

The underlying design principle of the MRA PIFA is to deliberately manipulate the PIFA patch structure, thereby changing the current distribution, to create three resonant current paths on the antenna surface, which delivers tri-band radiation behavior. Furthermore, the electrical lengths of the resonant current paths are altered through double-arm NEMS switches, to shift the location of the highest frequency band, thereby realizing penta-band behavior. As is seen in Figure 4, the MRA geometry incorporates three additional metallic patches $\mathrm{A}, \mathrm{B}$, and $\mathrm{C}$, which are either connected or disconnected from the main radiating patch surface through NEMS switches. Depending on the status of the interconnecting switches, the antenna works at three reconfigurable modes of operation, which is summarized in Table 1. For example, $\bar{A} B \bar{C}$ indicates that only the NEMS switches associated with patch B is ON (down state, cantilever is making contact with antenna metallization), whereas the rest are OFF (up state, cantilever is curled upward, i.e., no connection), which corresponds to Mode 1 operation.

\subsection{Interconnecting NEMS Switch}

The recent advancements in nanofabrication technologies, in particular on carbon nanotubes (CNTs), have been opening up new applications in many disciplines including RF systems. CNTs with remarkable mechanical and electrical properties exhibit an extremely high directional stiffness, accommodate very large mechanical strains, and depending on diameter and helicity, act as 1D metals or semiconductors. Because of these unique properties, coupled with their low mass and chemical inertness, CNTs represent ideal materials for enabling many high-performance NEMS devices [6]. Electromechanical CNT switches for high-frequency applications with switching times of a few nanoseconds and pull-down voltages less than $5 \mathrm{~V}$ have recently been reported [7]. Also, theoretical simulation results of nanotweezer and double-clamped metallic CNT switches integrated with microwave coplanar waveguide have been reported [8], which demonstrated their excellent low loss and high isolation characteristics in the range of 10-100 GHz. However, the integration of NEMS switches with antennas has not been fully investigated to date.

The schematic along with dimensions of double-arm NEMS switch of which architecture is identical to the MEMS switch is shown in Figure 4(c). The NEMS switch cantilever arm length and width are $L=3 \mu \mathrm{m}$ and $W=60 \mathrm{~nm}$, respectively. The distances between the radiating patch and the parasitic patches are kept at $100 \mu \mathrm{m}$. However, only $8 \mu \mathrm{m}(=2 \times L+S)$ of this gap is spanned by the double-arm NEMS switches as shown in Figure $4(\mathrm{c})$. The effective heights from the contact region of the NEMS cantilever to the bottom antenna metal and from the bias electrode to the NEMS cantilever are $1 \mu \mathrm{m}$ and $0.1 \mu \mathrm{m}$, respectively. DC bias voltages of NEMS switches are applied through high DC resistance Silicon Chrome $(\mathrm{SiCr})$ lines with a sheet resistance of $\sim 50 \mathrm{k} \Omega / \mathrm{square}$ and an absolute resistance of 500 $\mathrm{k} \Omega$. The resistance values of the bias lines were optimized for an effective biasing scheme which avoids electromagnetic (EM) coupling between radiating RF and DC control signals, thereby eliminating degradation in antenna radiation performance. Each 


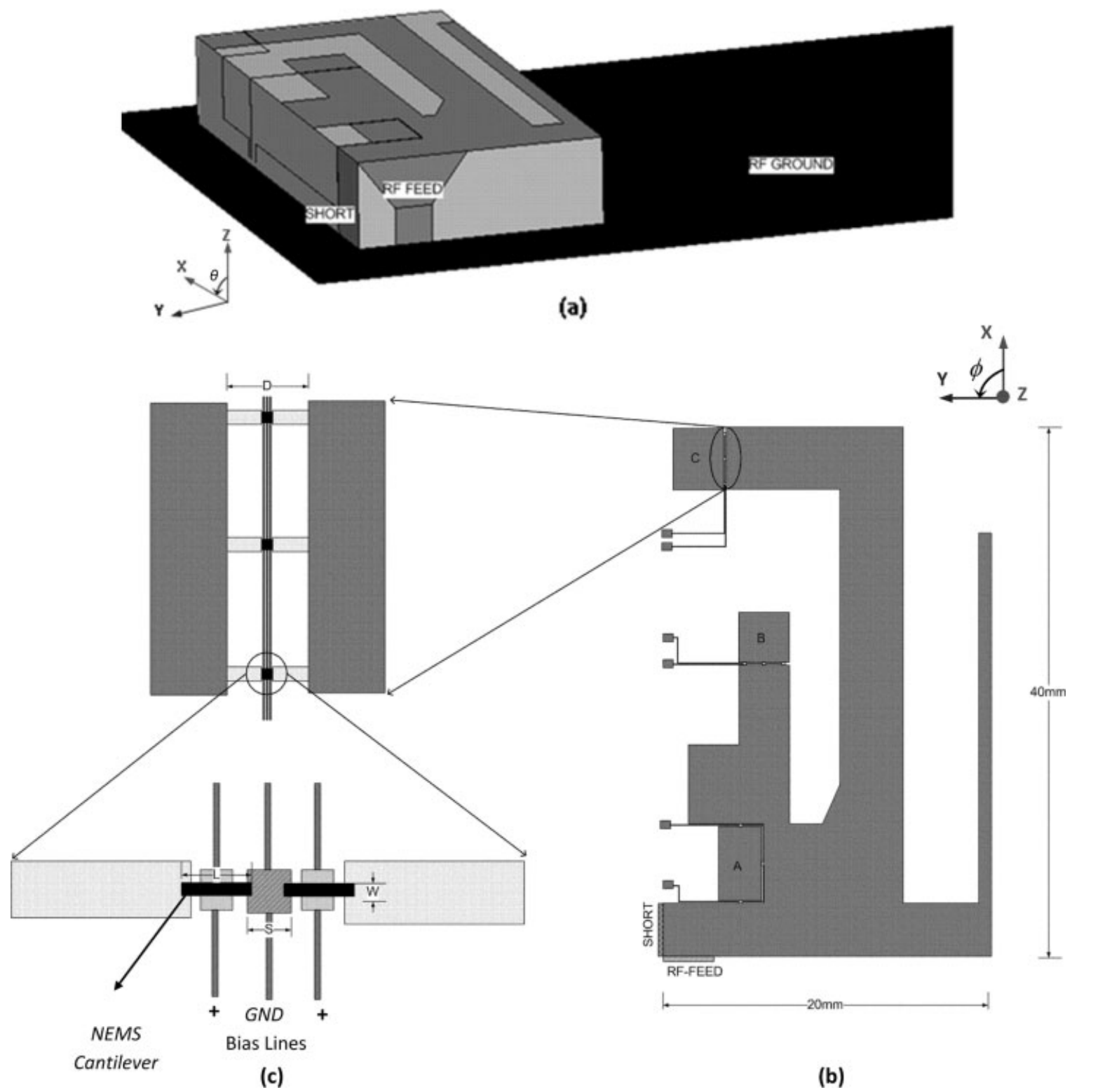

Figure 4 (a) 3D simulation schematic and (b) top-view of MRA PIFA ( $\phi$ is the azimuth angle measured from $x$-axis, and $\theta$ is the elevation angle measured from $z$-axis). (c) The magnified top-view of NEMS switch, $L=3 \mu \mathrm{m}, W=60 \mathrm{~nm}, S=2 \mu \mathrm{m}, D=100 \mu \mathrm{m}$

interconnecting NEMS switch has two high resistance DC bias lines, i.e., ground and signal, connected to it. One of the bias lines is connected directly to the metallic post, which is the fixed point of the NEMS switch, and the other is connected to a high-resistance electrode placed underneath the cantilever [Fig. $4(\mathrm{c})]$. Both the metallic posts and the bias electrodes are isolated structures, thereby providing individual control of each actuator without requiring additional DC blocks.

TABLE 1 Switch Status and Corresponding Mode of Operation

\begin{tabular}{lcclc}
\hline $\begin{array}{l}\text { Switch } \\
\text { Status }\end{array}$ & $\begin{array}{c}\text { Mode of } \\
\text { Operation }\end{array}$ & & Active Bands & \\
\hline $\bar{A} B \bar{C}$ & 1 & GSM900 & GPS1575 & GSM1800 \\
$A B C$ & 2 & GSM900 & GPS1575 & PCS1900 \\
$A \bar{B} C$ & 3 & GSM900 & GPS1575 & UMTS2100 \\
\hline
\end{tabular}

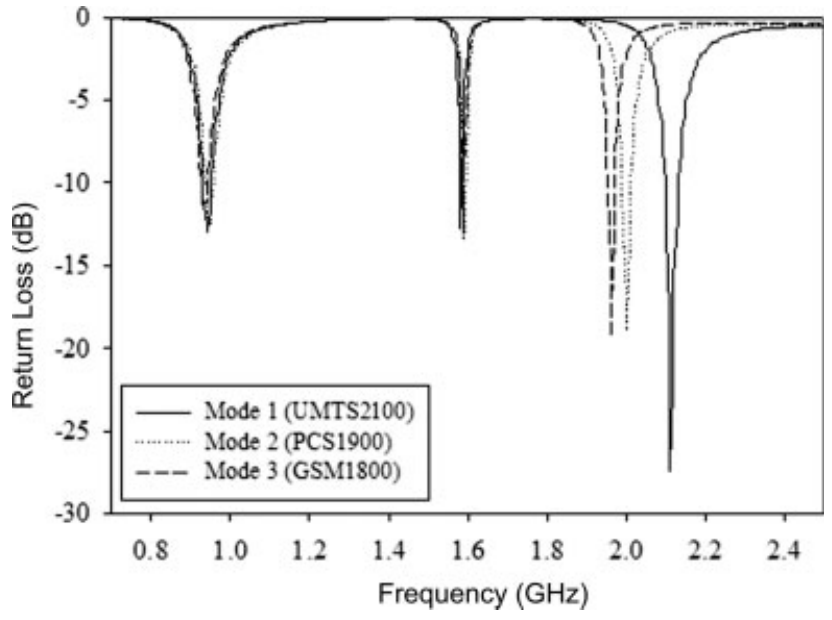

Figure 5 Return losses of the MRA PIFA for three reconfigurable modes of operation 

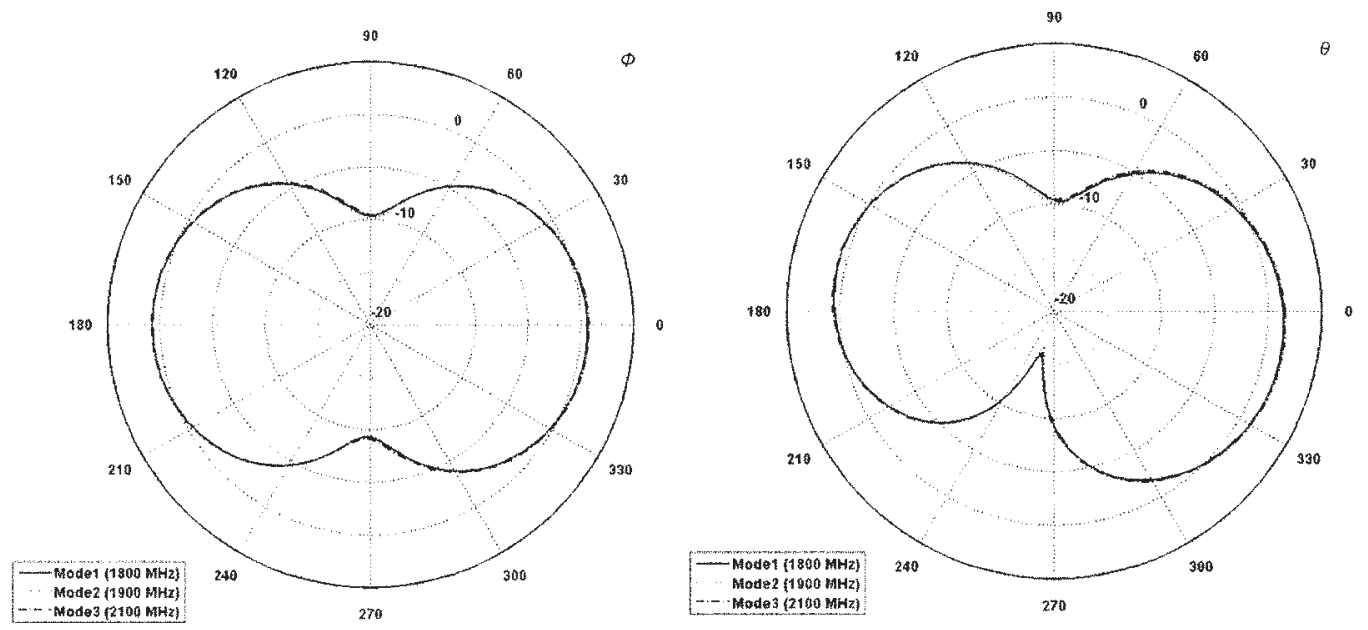

a)
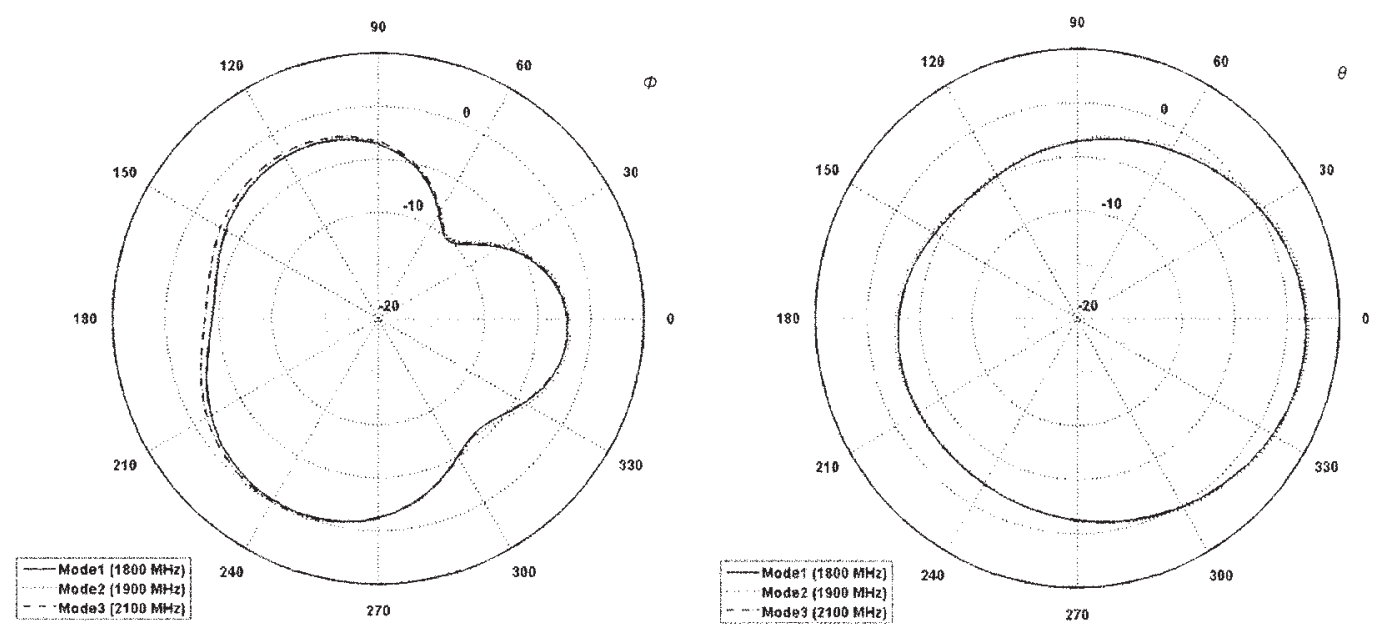

b)
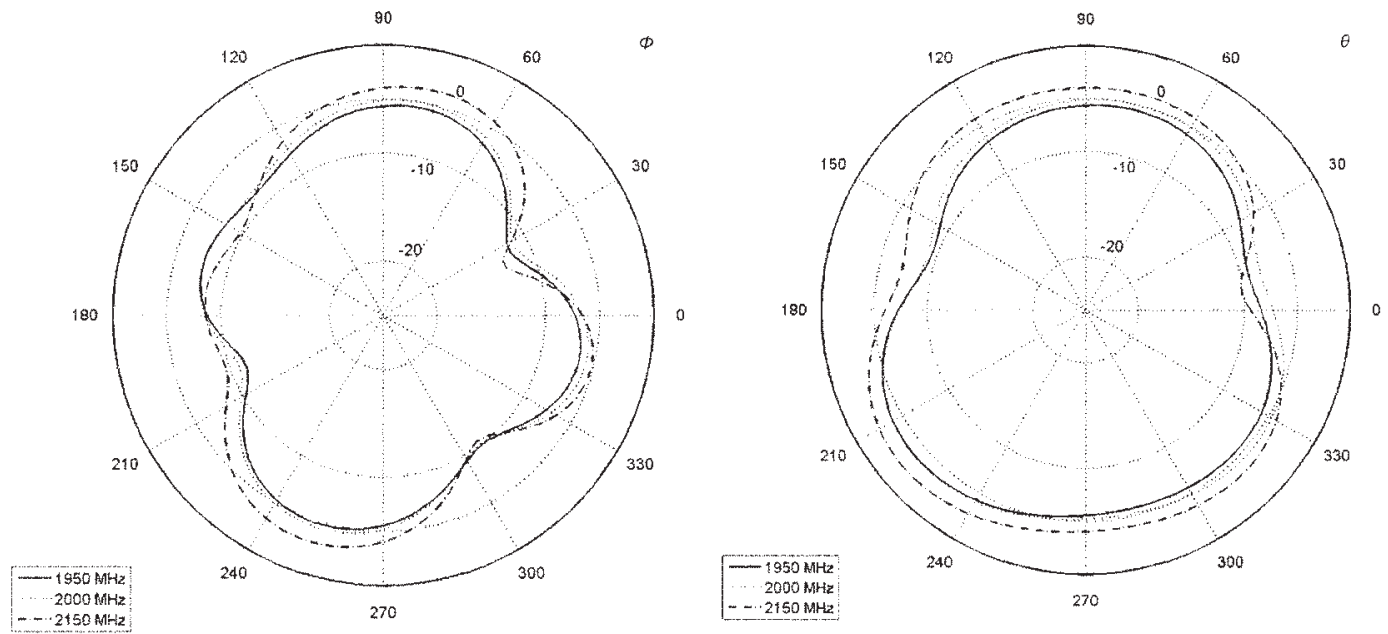

c)

Figure 6 The gain patterns for each mode of operation in Azimuth- and Elevation-planes ( $x-y$ and $y-z$ planes) (a) GSM 900 at 0.94 GHz, (b) GPS 1575 at $1.58 \mathrm{GHz}$, and (c) High bands at $1.95 \mathrm{GHz}, 2.0 \mathrm{GHz}$, and $2.15 \mathrm{GHz}$ 


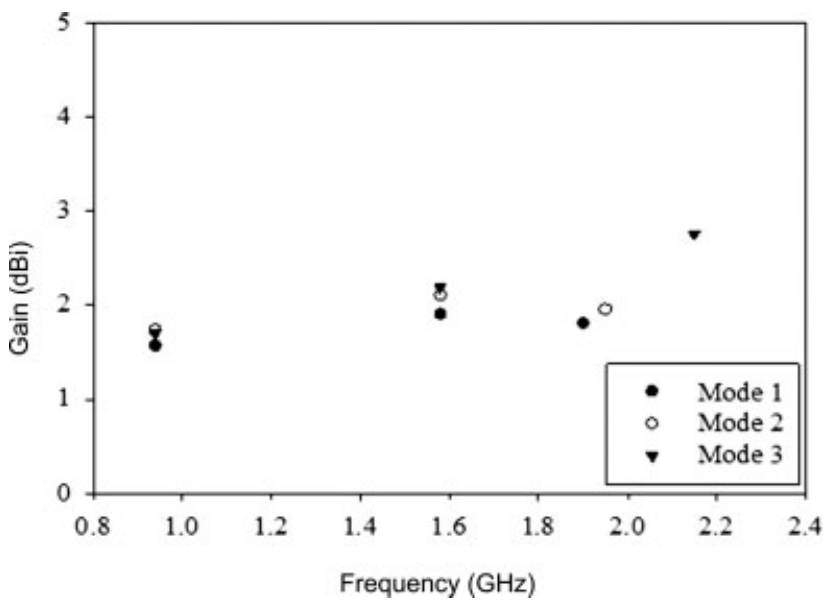

Figure 7 Maximum gain versus frequency for each mode of operation

Before carrying out the full-wave EM analyses, we have performed mechanical analyses by Coventor [9] to determine the actuation voltage, elastic force of the cantilever, and van der Waals force associated with each individual NEMS switch. The results yielded $\sim 10 \mathrm{~V}$ actuation voltage, $0.1 \mu \mathrm{N}$ elastic force, and $0.1 \mathrm{nN}$ van der Waals force. Elastic force being much larger than van der Waals force is required to ensure that the NEMS switch will return to its original state when the bias voltage is set to zero.

\section{RESULTS AND DISCUSSIONS}

The radiation and impedance analyses of the NEMS integrated MRA PIFA have been carried out using EM full-wave analysis tool HFSS by Ansoft [10]. The return losses of the antenna for each reconfigurable modes of operation as a function of frequency are shown in Figure 5. While GSM900 and GPS1575 frequencies remain almost unchanged for all of the modes, the other three frequencies (GSM1800, PCS1900, and UMTS2100) are excited by the proper actuation of interconnecting MEMS switches.

The gain patterns of the antenna for each mode of operation were taken in the principal cuts, elevation- and azimuth-planes, which correspond to $y-z(\phi=90)$ and $x-y(\theta=90)$ planes, respectively. The orientation of the antenna with respect to coordinate axis is shown in Figure 4. As shown in Figures 6(a)-6(c), the antenna maintains similar radiation characteristics and shows stable directional behaviors for each mode of operation, Mode 1, Mode 2, and Mode 3. It must be noted that although a nonreconfigurable single antenna may support multiple frequencies, the radiation pattern and gain values corresponding to each frequency can be significantly different. This, however, might be a problem for the next-generation multimode multiband wireless communications applications, where the radiation characteristics and gain performance are required to be similar over multiple frequencies. The MRA PIFA maintains the same radiation characteristics for all modes of operation. This is a consequence of a highly efficient MRA with a narrow instantaneous operating bandwidth (over which the radiation behavior remains almost constant) being tuned over a wider bandwidth. Figure 7 shows the gain variation at discrete operation frequencies corresponding to each mode of operation, where well gain flatness is observed over the reconfigurable modes of operation.

\section{CONCLUSIONS}

The full-wave analyses of a frequency reconfigurable antenna integrated with NEMS switches have been presented. The results revealed that NEMS switches from both mechanical and RF perspectives can be used as promising building blocks for establishing high-performance reconfigurable antennas for use in next generation multimode multiband wireless communication applications. We have also presented microfabrication and RF characterization of reduced-size MEMS switches. We are currently developing new nanofabrication processes for NEMS switch integrated reconfigurable antennas that can change not only frequency band but also polarization and radiation pattern of the radiated field.

\section{ACKNOWLEDGMENTS}

This work was supported by Award No. 2007-IJ-CX-K025 awarded by the National Institute of Justice, Office of Justice Programs, US Department of Justice. The opinions, findings, and conclusions or recommendations expressed in this publication/ program/exhibition are those of the authors and do not necessarily reflect the views of the Department of Justice. The microfabrication efforts have been performed in part at the Cornell NanoScale Facility, a member of the National Nanotechnology Infrastructure Network.

\section{REFERENCES}

1. B.A. Cetiner, et al., Monolithic integration of RF MEMS switches with a diversity antenna on PCB substrate, IEEE Trans Microwave Theory Tech 51 (2003), 332-335.

2. B.A. Cetiner and H. Jafarkhani, et al., Multifunctional reconfigurable MEMS integrated antennas for adaptive MIMO systems, IEEE Commun Mag 42 (2004), 62-70.

3. B. Akbar, M. Sayeed, and V. Raghavan, Maximizing MIMO capacity in sparse multipath with reconfigurable antenna arrays, IEEE J Select Topics Signal Process 1 (2007).

4. G.M. Rebeiz, RF MEMS: Theory, design and technology, Wiley, New York, 2003.

5. N. Biyikli, Y. Damgaci, and B.A. Cetiner, A low-voltage small-size double-arm MEMS actuator, IEE Electron Lett 45 (2009).

6. V. Sazanova, et al., A tunable carbon nanotube electromechanical oscillator, Nature 431 (2004), 284-287.

7. B. Kaul, et al., Electromechanical CNT switches for high-frequency applications, Nano Lett 6 (2006), 942-947.

8. M. Dragoman, et al., Nanoelectromechanical switches based on CNTs for microwave and millimeter waves, App Phys Lett 90 (2007).

9. CoventorWare, 3D MEMS software, Coventor Inc., NC, 2008.

10. Ansoft HFSS version 11, 3D EM-field simulation for high performance electronic design, Ansoft Corporation, Pittsburgh, PA, 2007.

(C) 2009 Wiley Periodicals, Inc. 